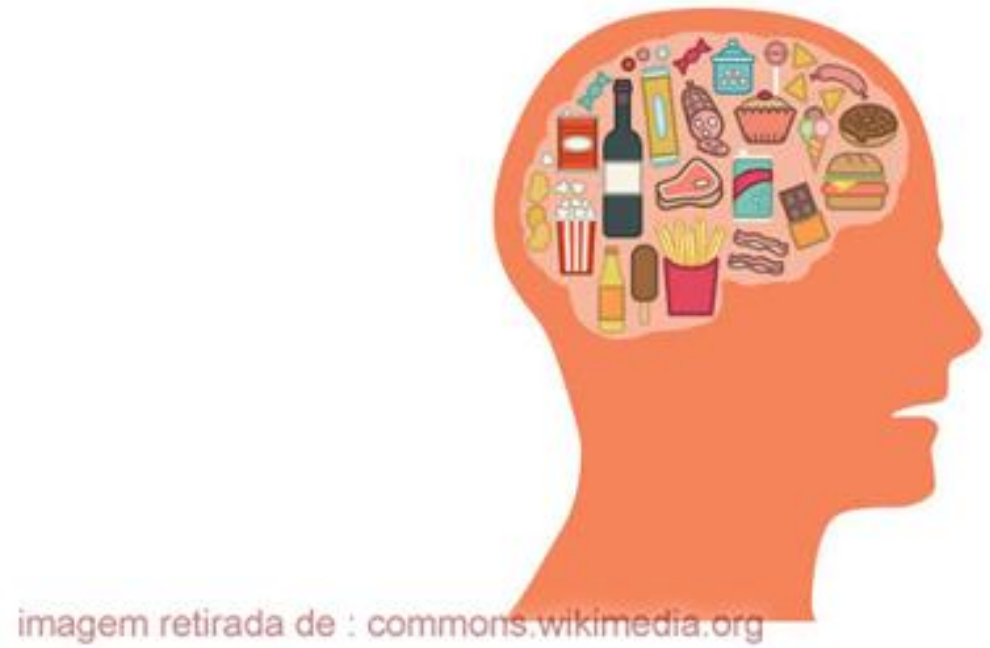

\title{
COMPULSÃO ALIMENTAR: UMA LEITURA PSICANALÍTICA
}

\author{
Monica Vianna \\ Psicóloga. Doutorado em Psicologia Clínica pela PUC-Rio. Mestrado em Psicologia pela PUC-SP. Pós- \\ Doutoranda em Psicologia Clínica da PUC-Rio. Especialização em Psicóloga Clínica pela PUC-Rio. E-mail: \\ viannamonica@hotmail.com

\section{Joana de Vilhena Novaes} \\ Psicanalista. Pós-doutorado em Psicologia Social e em Psicologia Médica pela Uerj. Especialista em Transtornos \\ Alimentares pela Santa Casa de Misericórdia do Rio de Janeiro.E-mail: joanavnovaes@gmail.com
}

Resumo: A alimentação, enquanto um aspecto da vida cotidiana do sujeito, é um veículo de produção de sentido e saúde. De modo que a comensalidade trata de um comportamento coletivo, além de individual. No Brasil, nas últimas décadas, observou-se mudanças significativas nos aspectos subjetivos ligados ao comer. O presente artigo tem como objetivo propor uma reflexão sobre os aspectos psíquicos associados à Compulsão Alimentar, a partir de uma perspectiva teórica psicanalítica. Para tanto, voltamos nosso olhar para os primórdios do desenvolvimento infantil respaldados pelos conceitos de introjeção canibal de Melanie Klein (1957) e de objeto absolutamente necessário do André Green (2009). Além disso, aventaremos algumas semelhanças e dissonâncias conceituais entre adição, impulsividade e compulsão, visando aprofundar a compreensão da C.A sob o prisma desses constructos teóricos.

Palavras-chave: Corpo. Psicanálise. Adição. Impulsividade. Compulsão alimentar.

\section{BINGE EATING: A PSYCHOANALYTIC VIEW}

Abstract: Food, as an aspect of the subject's daily life, is a vehicle of meaning and health production. So that the commensality deals with a collective behavior, besides being individual. In Brazil, in recent decades, there have been significant changes in subjective aspects related to eating. This article aims to propose a reflection on the psychic aspects associated with Eating Compulsion, from a psychoanalytic theoretical perspective. To this end, we turn our gaze to the beginnings of child development backed by the concepts of cannibal intrusion of Melanie Klein (1957) and an absolutely necessary object of André Green (2009). In addition, we will make some similarities and conceptual dissonances between addition, impulsivity and compulsion, aiming to deepen the understanding of binge eating from the perspective of these theoretical constructs.

Keywords: Body. Psychoanalysis. Addition. Impulsivity. Binge eating.

\section{POLÊM!CA $\mid$ LABORE}

Polêmica - Revista Eletrônica da Uerj - Rua São Francisco Xavier, 524, $1^{\circ}$ andar bloco D, sl.1001 • Tels.: +55 21 2334-4088 / 4087 • http://www.e-publicacoes.uerj.br/index.php/polemica/index http://www.labore.uerj.br • laboreuerj@yahoo.com.br 


\section{Introdução}

$\mathrm{Na}$ contemporaneidade, o corpo assume o lugar de capital (BOURDIEU, 1980), tornando-se lócus fundamental de investimentos, além de uma fonte, inequívoca, de sofrimento psíquico. Simultaneamente, a comida, enquanto um valor e, igualmente, um bem de consumo de mais fácil acesso, fez com que migrássemos da desnutrição, como um sintoma social das classes populares. Neste sentido, a obesidade converte-se, no cenário atual, em um problema de saúde pública que atinge, majoritariamente, os setores menos favorecidos da população brasileira (NOVAES, 2010). Aos discursos normativos credita-se às funções prescritivas relativas à promoção da saúde. Tal fato, gerou uma mudança de costumes, como também do perfil epidemiológico de algumas doenças relacionadas ao comportamento alimentar.

O corpo entrou em cena e com ele inúmeras práticas para se fugir da feiura, ancoradas na premissa de que a adesão à corpolatria está associada às práticas de bem viver, bem como à tentativa de escapar da exclusão socialmente validada, gerada pela gordura (NOVAES, 2006).

Sendo assim, dentro deste cenário, o que levaria ao crescimento da incidência das patologias ligadas aos transtornos da oralidade, além da inequívoca constatação de um agudo sofrimento psíquico ligado à imagem corporal?

Para responder a tal indagação, é necessário tomar como ponto de partida um dos grandes paradoxos do culto ao corpo na sociedade de consumo: o fato de sermos, em um só tempo, uma cultura obesogênica e lipofóbica. Adicionalmente, o sujeito é responsabilizado pela sua aparência, imputando-lhe a culpa por quaisquer eventuais desvios estéticos (BAUDRILLARD, 1970).

Neste sentido, a beleza deixou de ser um direito para transformar-se em um dever, solo fértil para o crescimento das chamadas Doenças da Beleza ${ }^{1}$ - uma das expressões contemporâneas do mal-estar vivido no corpo, observado através dos casos clínicos de dismorfia corporal e transtornos alimentares, cada vez mais frequentes. Atualmente, com uma taxa de incidência que equivale à 4,6\% da população brasileira (DUCHESNE et al., 2007).

O presente artigo tem como objetivo refletir sobre alguns mecanismos psíquicos associados à Compulsão Alimentar. Para tal, a psicanálise será usada como o eixo teórico que norteará esse estudo. A fim de investigar os primórdios das formações subjetivas relativos à

\footnotetext{
${ }^{1}$ Termo cunhado por Sergio Aguiar de Medeiros em tese de Doutorado defendida no Departamento de Psicologia da PUC-Rio e publicada em livro: O belo e a morte: estética, angústia e desejo, da editora Juruá, 2012.
}

\section{POLÊM!CA LABORE}

Polêmica - Revista Eletrônica da Uerj - Rua São Francisco Xavier, 524, $1^{\circ}$ andar bloco D, sl.1001 • Tels.: +55 21 2334-4088 / 4087 • http://www.e-publicacoes.uerj.br/index.php/polemica/index http://www.labore.uerj.br • laboreuerj@yahoo.com.br 
temática, serão analisados os conceitos psicanalíticos de introjeção canibal de Melanie Klein (1957) e objeto absolutamente necessário de André Green (2009). Adicionalmente, uma análise comparativa entre adição, impulsividade e compulsão será, aqui, apresentada com o intuito de destacar similitudes e dissonâncias entre os referidos constructos teóricos.

\section{Parece mais não é: compulsão, transtorno alimentar e obesidade}

A compulsão alimentar (CA) é um sintoma encontrado em diversos quadros de transtornos alimentares (TA), mas também pode ocorrer isoladamente, em episódios pontuais que caracterizem uma manifestação clínica, mas não preencham, necessariamente, todos os critérios diagnósticos para um TA. Assim sendo, a CA se apresenta em um largo espectro que vai desde episódios esporádicos, com baixo comprometimento psíquico, físico e social para o sujeito, até um quadro de TA grave e debilitante.

As diferenças entre exagero alimentar (ou excesso alimentar), compulsão e obesidade são noções básicas que permeiam o campo das psicopatologias alimentares, mas ainda causam dúvida e confusão até mesmo entre profissionais de saúde.

Os episódios de exagero ou excesso alimentar não são incomuns em uma sociedade obesogênica como a nossa, podendo ocorrer em eventos nos quais a comida assume protagonismo, e o consumo de uma grande quantidade e variedade de alimentos palatáveis é estimulado em inúmeros eventos sociais (festas, comemorações ao redor da mesa, churrascarias, rodízio ou buffet all you can eat), que fazem da comensalidade um importante aspecto das sociabilidades. Nessas ocasiões, comer mais do que é necessário ou do que é usual no cotidiano pode caracterizar um exagero alimentar, mas não necessariamente uma CA.

Nos episódios de CA, a pessoa sente a necessidade de comer, mesmo quando não está com fome, não deixando de se alimentar apesar de já estar satisfeita. Ocorre, assim, a ingestão de uma grande quantidade de alimento, num período limitado de tempo, acompanhado da sensação de perda de controle sobre o ato. $O$ sujeito não consegue controlar a quantidade, tampouco a forma como ocorre a ingesta da comida. Por essas razões, os episódios costumam ocorrer escondidos, sendo interrompidos, apenas, por fatores externos à vontade do sujeito, como no caso da chegada de alguém, do término dos alimentos ou mesmo pelo mal-estar físico decorrente do empanzinamento. Após a compulsão, são intensos os sentimentos de culpa, vergonha e tristeza (VIANNA, 2019).

\section{POLÊM!CA $\mid$ LABORÊ}

Polêmica - Revista Eletrônica da Uerj - Rua São Francisco Xavier, 524, $1^{\circ}$ andar

bloco D, sl.1001 • Tels.: +55 21 2334-4088 / 4087 • http://www.e-publicacoes.uerj.br/index.php/polemica/index

http://www.labore.uerj.br • laboreuerj@yahoo.com.br 
A CA não está ligada ao prazer alimentar à mesa; pelo contrário, ela é um transtorno psiquiátrico que está presente em alguns Transtornos Alimentares como, por exemplo, a bulimia nervosa (BN) e o transtorno da compulsão alimentar (TCA). O termo "compulsão alimentar" será empregado no contexto deste artigo para designar qualquer conduta sentida pelo sujeito como uma obrigação de comer, e julgada, por ele, como reflexo de uma excessiva falta de controle. Tal comportamento repete-se com frequência muito variável, seguido, contudo, invariavelmente de sentimentos depreciativos como culpa e vergonha.

Já a obesidade é uma doença caracterizada pelo excesso de gordura no corpo, que frequentemente causa danos à saúde. Ela é tratada como doença, pois diminui a qualidade e a expectativa de vida. Segundo a Organização Mundial de Saúde trata-se de uma doença multifatorial, na qual estão envolvidas alterações morfológicas: endocrinológicas, nutricionais e metabólicas, e não um distúrbio mental ou comportamental.

Logo, a obesidade não é classificada como um transtorno psiquiátrico (HALMI, 1994; APA, 2013). Não há um perfil psicológico ou uma estrutura psíquica única para todos os indivíduos obesos, sendo temerária a generalização dos problemas psicológicos para todos os casos de obesidade. Além disso, a CA não ocorre, exclusivamente, em pessoas obesas e nem todos os obesos apresentam episódios de CA. Por esta razão, no presente artigo, será lançado um olhar para a psicopatologia da CA e não da obesidade.

$\mathrm{O}$ excesso de peso não é um critério de diagnóstico para CA, todavia, esse quadro clínico, com frequência, está associado ao sobrepeso e aos diversos graus de obesidade. Enquanto a prevalência da TCA, estimada na população em geral, pode variar entre 1,8\% e $4,6 \%$, aproximadamente, e $30 \%$ dos indivíduos obesos que procuram tratamento para emagrecer apresentam esse transtorno (DUCHESNE et al., 2007).

Apesar de não possuir vinculação irrestrita com a obesidade, o subgrupo de obesos com CA manifesta pior resposta aos tratamentos que objetivam emagrecimento, com maior dificuldade para perder peso, pior manutenção do peso perdido e maior taxa de abandono dos tratamentos. Além disso, eles apresentam maior prevalência da flutuação de peso e passam mais tempo de suas vidas tentando emagrecer (DUCHESNE et al., 2007).

Os obesos compulsivos diferem significativamente dos obesos sem CA, apresentando níveis elevados de comorbidades psiquiátricas, com início precoce da doença e maior gravidade da obesidade. É fundamental levar em consideração as características compulsivas na análise e tratamento desses pacientes (AZEVEDO; SANTOS; FONSECA, 2004).

\section{POLÊM!CA $\mid$ LABORÉ}

Polêmica - Revista Eletrônica da Uerj - Rua São Francisco Xavier, 524, $1^{\circ}$ andar

bloco D, sl.1001 • Tels.: +55 21 2334-4088 / 4087 • http://www.e-publicacoes.uerj.br/index.php/polemica/index http://www.labore.uerj.br • laboreuerj@yahoo.com.br 


\section{Transtornos Alimentares, psicodinâmica e manejo}

Os Transtornos Alimentares, especialmente nas últimas décadas, têm sido objetos de muitas investigações científicas. Pesquisadores como Brian Lask (2000) e J. Mitchel (2001) apontam o caráter multifatorial na etiologia e são unânimes em reconhecer os aspectos constitucionais, sociais, culturais, familiares e de personalidade na origem desses distúrbios, parecendo haver um consenso acerca de uma abordagem multidisciplinar para que haja maior adesão desse tipo de paciente ao tratamento.

Vale ressaltar que a função da prática psicanalítica precisa ser revista como mais um recurso a ser utilizado no tratamento, o que, indubitavelmente, requer adaptações. Como afirma Jeammet (1999a), a abordagem psicanalítica pode-se apresentar sob duas vertentes: uma clássica, com adaptações da psicoterapia analítica no quadro de uma relação dual, e outra que integre uma série de abordagens multidisciplinares, incluindo demais técnicas e profissionais.

A direção do tratamento analítico, ainda que centrada no sintoma, tem como objetivo ir além do seu desaparecimento, visando à elaboração do conflito subjacente a ele. Dentro dessa perspectiva, o sintoma é uma solução de compromisso entre o desejo inconsciente e a censura psíquica, ou seja, um representante desse conflito. Se eliminado, mas não resolvido, ele pode retornar ou ser substituído por outro diferente.

Da mesma forma, as crises bulímicas e a recusa anoréxica podem ser compreendidas como comportamentos substitutos da elaboração psíquica esperada na resolução de conflitos intrapsíquicos. E sendo assim, Anorexia e Bulimia podem assumir uma variedade de significados, desde dificuldades nos processos de individuação experimentados na adolescência, até uma acentuada sensibilidade às mudanças socioculturais.

A compreensão da psicopatologia desses casos viabilizaria tanto a sustentação psicodinâmica quanto a orientação para o trabalho psicoterapêutico, como também algumas diretrizes que ajudem a mapear os modos de examinar esse tipo de sujeito.

Sentimentos como a avidez ou o repúdio serão evocados no vínculo transferencial com o terapeuta. Os pacientes com esse tipo de distúrbio encenam, através de problemáticas relacionadas ao narcisismo, questões relativas aos processos de diferenciação e formação identitária. Isso, por conseguinte, remontaria às fases mais primitivas do desenvolvimento infantil e, em última análise, ao nascedouro do psiquismo per se.

Falhas nesse processo são capazes de promover dificuldades importantes tanto na construção do processo identitário como na discriminação dos limites entre mundo interno e

\section{POLÊM!CA LABORÊ}

Polêmica - Revista Eletrônica da Uerj - Rua São Francisco Xavier, 524, $1^{\circ}$ andar

bloco D, sl.1001 • Tels.: +55 21 2334-4088 / 4087 • http://www.e-publicacoes.uerj.br/index.php/polemica/index http://www.labore.uerj.br • laboreuerj@yahoo.com.br 
externo. Observa-se, por exemplo, em pacientes com Transtornos Alimentares, que o laço transferencial assume um caráter aderente e/ou adesivante. Da mesma forma, sujeitos com compulsão alimentar são susceptíveis à adesão maciça a uma narrativa de si, que é fruto de um superego tirânico e persecutório. Disto derivariam, inclusive, as distorções da imagem corporal, tão frequentes nesses casos.

Para Jeammet (1999a, 1999b), são sujeitos cuja "autoestima é tributária deste suporte externo" (1999a, p. 119), o que os levaria a oscilar da polaridade de uma dependência idealizada à uma autossuficiência quase autística. Nos casos clínicos, trata, pois, da vulnerabilidade bulímica à rigidez anoréxica. Essa suscetibilidade narcísica imporia ao analista a necessidade de reconsiderar alguns manejos, especialmente, no que diz respeito às interpretações. Cuidado, igualmente, recomendado às intervenções feitas por outros profissionais da área de saúde.

Scazufca e Berlink (2004) destacam, entretanto, que muitos estudos psiquiátricos não recomendam o tratamento psicanalítico para os transtornos alimentares, sob o argumento de sua pouca eficácia. Tal posição merece algumas considerações. Segundo os autores, a sugestão tem origem nos estudos de Hilde Bruch, (HILDE BRUCH, 1973 apud SCAZUFCA; BERLINK, 2004.) com pacientes anoréxicas, que apresentavam como característica principal a pouca autonomia e a queixa de que suas mães sempre falavam por elas.

Todavia, no enquadre analítico, as interpretações dos significados inconscientes feitas pelo analista reforçariam, na transferência, o vínculo de dependência e repetiriam as suas vivências de invasão. Por este motivo, Bruch recomendava que o analista tivesse uma atitude mais ativa e que estimulasse as pacientes a pensarem por si próprias. Desse modo, a psicanálise, em seus moldes tradicionais, precisou submeter-se a uma série de adaptações ao ser eleita como terapêutica no tratamento dos Transtornos Alimentares.

Fiorini (2004) ressalta o caráter tecnicamente inovador desse tipo de contrato, o aproximando do que nomeou de "patologias narcisistas de intervenção vincular". Elas compreenderiam uma vasta gama de intervenções ativas, no tocante ao vínculo com o paciente, podendo assim desejar e manifestar que o paciente não morresse de inanição.

Informado pela proposição de uma adequação técnica, o analista poderia manifestar a necessidade de manter contato com os outros profissionais que acompanhe o paciente e também com sua família. Fiorini (1999) destaca em suas observações o fato desses pacientes não se beneficiarem do uso do divã, sendo a posição face a face a mais recomendada, uma vez que

\section{POLÊM!CA $\mid$ LABORE}

Polêmica - Revista Eletrônica da Uerj - Rua São Francisco Xavier, 524, $1^{\circ}$ andar bloco D, sl.1001 • Tels.: +55 21 2334-4088 / 4087 • http://www.e-publicacoes.uerj.br/index.php/polemica/index http://www.labore.uerj.br • laboreuerj@yahoo.com.br 
precisam "ser vistos" pelo analista, além de usá-lo em sua função de espelho, pelo menos até que a sua capacidade simbólica seja restaurada.

\section{Dos primórdios: adição, compulsão e impulsividade}

De um modo geral, os estudos psicanalíticos sobre TAs apontam para dificuldades nos laços mais precoces da relação materna e seus desdobramentos, especialmente na época da adolescência (BRUCH, 1974; JEAMMET, 2003; MIRANDA, 2003). Para tentar compreender melhor os arranjos que levaram a essa fixação na alimentação e no corpo, voltaremos aos elementos arcaicos, as fases mais primitivas da libido e as relações objetais, nas quais a relação precoce mãe-bebê coloca em primeiro plano as vicissitudes da função alimentar no exercício da função materna.

Partindo da noção de um aparato psíquico que é eminentemente sensório/afetivo/corporal - o corpo aqui tratado em sua função relacional, que afeta e é afetado pelo outro - intenciona-se também uma reflexão das diferenças e semelhanças entre Adição, Compulsão, e Impulsividade. Por vezes, esses termos são usados de forma equivalente, mas aqui apostamos em olhar suas particularidades, em tentar encontrar indícios das suas sutilezas e peculiaridades que ajudem nossa análise sobre a CA.

Buscaremos, dessa forma, construir uma leitura psicanalítica, não exclusiva nem excludente, sobre os aspectos psíquicos desse fenômeno pensado por diversas áreas de conhecimento e correntes teóricas, visto que se tornou um tema cada vez mais frequente nos consultórios médicos, clínicas psicológicas, atendimentos nutricionais e até mesmo nas redes sociais.

\section{Introjeção Canibal}

Winnicott (1975) afirma que a construção de bases narcísicas suficientemente estáveis propicia à criança um sentimento de segurança e continuidade, sendo fundamentais para que elas possam se manter no futuro com os seus próprios recursos. Os pacientes com CA demonstram uma fragilidade narcísica que pode ser percebida tanto nas características de suas modalidades relacionais objetais quanto no olhar que lançam sobre si mesmos, em sua relação com seu corpo e com a alimentação.

A intensidade e mesmo a avidez da CA refletem a importância do engajamento narcísico. Essas características trazem a marcadas insuficiências das internalizações e das bases

\section{POLÊM!CA LABORÉ}

Polêmica - Revista Eletrônica da Uerj - Rua São Francisco Xavier, 524, $1^{\circ}$ andar bloco D, sl.1001 • Tels.: +55 21 2334-4088 / 4087 • http://www.e-publicacoes.uerj.br/index.php/polemica/index http://www.labore.uerj.br • laboreuerj@yahoo.com.br 
narcísicas. Jeammet (1999a) aponta que, na tentativa de assegurar um equilíbrio narcísico, esses pacientes ficam excessivamente dependentes do olhar do outro, em detrimento de seus próprios investimentos.

Klein (1993) afirma que as falhas precoces na relação mãe-bebê estão envolvidas em um processo de clivagem, que tanto enfraquece a instância egóica quanto compromete sua capacidade de lidar com as forças pulsionais, instaurando uma fixação objetal diante da presença/ausência maciça do objeto amoroso, o que favorece uma conduta compulsiva.

Segundo a autora, as trocas com o mundo externo são reguladas por dois mecanismos: a introjeção e a projeção. Eles estabelecem o metabolismo básico de intercâmbio, entre um dentro e um fora, que se constitui através da entrada e saída de bons e maus objetos. A constituição dos bons e maus objetos se dá por meio da interação entre os cuidados maternos (presentes ou ausentes) e os impulsos amorosos e agressivos da criança.

Para os kleinianos, uma introjeção normal seria a capacidade de assimilar os aspectos bons do objeto, ao passo que uma introjeção canibal é a introdução do objeto destroçado, destituído de valor, com o qual ocorre a identificação.

A introjeção do objeto bom é o processo de pôr dentro do aparelho psíquico todas as experiências de prazer, formando uma reserva interna de vivências prazerosas que pode funcionar como um porto seguro, uma garantia de acesso ao prazer e à segurança. Dessa forma, a capacidade de tolerar a frustração aumenta, levando a um aumento de tolerância à própria realidade psíquica.

Leva tempo para a criança aceitar uma posição de poder relativamente frágil, que demanda paciência para esperar os momentos de satisfação. Esse processo está vinculado à capacidade de tolerar as frustrações, que, por sua vez, depende do estabelecimento do objeto bom internamente.

Por outro lado, se o objeto primário for introjetado de forma canibal, a mãe cuidadora não será sentida como presente no psiquismo da criança e não se criará um substituto para a presença da mãe que assegure a possibilidade de lidar com a sua ausência concreta, o que garantiria um apaziguamento diante dos excessos pulsionais.

Essa introjeção canibal do objeto primário reflete o desamparo do sujeito diante das pulsões e deixa-o desprotegido diante da perda do objeto. Consequentemente, o sujeito passa a buscar nos objetos externos (neste caso, a comida) uma ilusão de preenchimento do sentimento de vazio, da angustia e da frustração com as quais não consegue lidar. Sendo assim, o sujeito

\section{POLÊM!CA LABORE}

Polêmica - Revista Eletrônica da Uerj - Rua São Francisco Xavier, 524, $1^{\circ}$ andar

bloco D, sl.1001 • Tels.: +55 21 2334-4088 / 4087 • http://www.e-publicacoes.uerj.br/index.php/polemica/index http://www.labore.uerj.br • laboreuerj@yahoo.com.br 
utiliza o alimento como substituto do objeto bom faltante em seu mundo interno; essa tentativa, porém, não é bem-sucedida, desencadeando uma fixação no objeto, além de uma busca incansável e infrutífera.

O processo de introjeção normal possibilita a superação da dependência do sujeito ao objeto, permitindo a expansão de seus investimentos libidinais em direção a um vasto campo de objetos substitutos. Esse processo envolve um trabalho de luto e de elaboração da experiência de perda e representa, consequentemente, um processo de mudança psíquica, que deve reorganizar-se em função da assimilação das propriedades do objeto.

\section{Objeto Absolutamente Necessário}

O conceito de "objeto absolutamente necessário" desenvolvido por André Green estáligado à teoria do "trabalho do negativo" (GREEN, 1986, 1988), da "articulação do duplolimite" (GREEN, 1982) e busca explicar a falha na introjeção do primeiro objeto amoroso que poderia vir a desencadear um processo equivalente ao da introjeção canibal (conceito kleiniano).

A principal característica do objeto absolutamente necessário, conforme proposto por Green, é deixar-se apagar. Trata-se do objeto efetivamente perdido, pelo qual se pode fazer o luto, ao contrário do objeto da melancolia. Segundo o autor, o objeto absolutamente necessário é o que mais contribui para os processos de constituição da subjetividade.

Quando a mãe, enquanto objeto absolutamente necessário, deixa-se apagar, corresponde a um movimento pulsional com as marcas do trabalho do negativo. Esse movimento ocorre tanto na constituição do próprio objeto, quanto na atenuação de sua presença. Dessa forma o vazio pode ser internalizado na forma de estrutura, o que estamos chamando aqui de vazio interno estruturante.

Todavia, se o objeto absolutamente necessário não chega a se dissipar, ocorre uma espécie de distorção dessa função do objeto, ou seja, algo se desvia e fracassa em sua função de objeto. Esse fracasso diz respeito à impossibilidade do objeto falhar, enganar-se, negativarse.

A falibilidade do objeto viabiliza a ocorrência de um duplo movimento de negação, no qual o objeto é esquecido e convertido em estrutura psíquica (vazio interno estruturante), e concomitantemente desintegra-se ressurgindo como outros objetos de atração e repulsa. Nos sujeitos com CA, essa dupla negação, de certa forma, está comprometida, e o vazio interno

\section{POLÊM!CA $\mid$ LABORE}

Polêmica - Revista Eletrônica da Uerj - Rua São Francisco Xavier, 524, $1^{\circ}$ andar

bloco D, sl.1001 • Tels.: +55 21 2334-4088 / 4087 • http://www.e-publicacoes.uerj.br/index.php/polemica/index http://www.labore.uerj.br • laboreuerj@yahoo.com.br 
estruturante não se funda. Na falta desse vazio estrutural, a vivência de um sentimento de vazio advém da incapacidade de conter as angústias do ego e apresenta-se na relação de avidez e hostilidade com a comida.

O sujeito com CA não tem uma relação prazerosa com a comida. A necessidade do alimento é vivenciada com grande intensidade, levando a um ataque de comer que prescinde da fome e do paladar. Muito diferente da experiência de um gourmet que degusta sem pressa, sentindo o despertar das papilas gustativas. $\mathrm{Na} \mathrm{CA}$, temos um empanturramento, acompanhado de sentimentos negativos como a vergonha e a tristeza.

De acordo com André Green (2009), o "trabalho do negativo" implica uma dissolução do objeto em si, com consequente abertura à diferença. A compulsão por outro lado, aponta para um elo com um objeto não transformável. O objeto do desejo transforma-se em objeto de necessidade, pois, no registro da necessidade aditiva, ocorre uma diminuição do desejo em relação à necessidade, e do afeto em relação à sensação.

Figueiredo e Cintra (2004), ao falarem do objeto absolutamente necessário, propõem a existência de dois tempos, no primeiro tempo temos uma função intrínseca e paradoxal do objeto, que está lá para estimular e despertar a pulsão e, ao mesmo tempo, para contê-la. Logo, estimular e conter a pulsão são suas funções que devem ser internalizadas, para o objeto deixarse apagar.

Nos pacientes com CA, é possível perceber, através de suas dificuldades em lidar com as carências e excessos pulsionais, que as funções estimulante e de continência foram precariamente exercidas e mal internalizadas. Haverá, mais adiante, um paralelo entre as funções estimulante e de continência pulsionais com a impulsividade e a compulsividade presentes na CA.

No segundo tempo, o objeto absolutamente necessário tem a função de conferir a noção da necessidade de se aceitar que há mais de um objeto. Melhor dizendo, o objeto é negado e posto à distância; assim, desdobra-se em uma multiplicidade de objetos substitutivos e contingentes, sempre inadequados, falíveis e substituíveis.

Segundo Figueiredo e Cintra (2004) essa função é muito importante, pois revela uma forma de presença-ausente do objeto absolutamente necessário que será inscrito no psiquismo como estrutura e vazio. Tal presença-ausente é a base da tolerância a todas as distâncias, ausências e inadequações dos objetos substitutivos. Nas palavras dos autores, "tanto a 'ausência da ausência' quanto a 'presença da presença' desconhecem o vazio. Em ambos os casos o

\section{POLÊM!CA LABORE}

Polêmica - Revista Eletrônica da Uerj - Rua São Francisco Xavier, 524, $1^{\circ}$ andar bloco D, sl.1001 • Tels.: +55 21 2334-4088 / 4087 • http://www.e-publicacoes.uerj.br/index.php/polemica/index http://www.labore.uerj.br • laboreuerj@yahoo.com.br 
processo de constituição psíquica fica obstruído, ou seja, o primeiro tempo não se consuma e o segundo tempo não se instala" (FIGUEIREDO; CINTRA, 2004, p. 20).

Para Green (2009), a pulsão é negativada ao ser contrariada, quando lhe são impostas diferenças, escolhas, renúncias e moderação, ou seja, quando a escolha é possível, pois ela sempre envolve uma renúncia, a qual implica não mais querer tudo como alvo da voracidade pulsional.

A recusa do objeto absolutamente necessário em deixar-se negativar pode levar a uma falta de estimulação e de contenção das pulsões. Além disso, o objeto não pode ser substituído por uma multiplicidade de outros objetos contingentes e falíveis, nem se desenvolve a base da tolerância a todas as distâncias, ausências e inadequações dos objetos substitutivos.

Dentro do contexto da CA aqui apresentado, pode-se pensar que uma das consequências do não apagamento do objeto absolutamente necessário seria a introjeção canibal do objeto primário que levaria a não superação da dependência do sujeito em relação ao objeto e a um empobrecimento do contato com a realidade interna.

Destituído de valor é introjetado (introjeção canibal) ocorrendo assim este tipo de identificação. Ao invés de se identificar com o objeto cuidador e protetor, o sujeito identificase com o objeto destruído. A identificação primária com o objeto destroçado levará a um comprometimento das identificações secundárias relacionadas à organização edípica (FIGUEIREDO; CINTRA, 2004).

No lugar do vazio interno estruturante, que deveria fundar-se a partir do apagamento do objeto absolutamente necessário, quando ocorre a introjeção canibal do objeto acontece a fixação no objeto e as dificuldades em lidar com as carências e excessos pulsionais que segunda nossa leitura contribuem para a CA.

\section{Adição: fixação no objeto}

As condutas compulsivas são complexas e convocam interlocução entre vários elementos que se comunicam de forma intrincada, promovendo diferentes intensidades e arranjos. Será explorado um pouco desse emaranhado de relações, pensando as interseções entre a compulsão, a adição e a impulsividade.

Tanto as compulsões quanto as adições refletem a instabilidade da organização psíquica subjacente. Seu aparecimento não assinala em si a presença de uma estrutura psíquica particular, mas parece testemunhar uma vulnerabilidade do ego e uma instabilidade do

\section{POLÊM!CA $\mid$ LABORÊ}

Polêmica - Revista Eletrônica da Uerj - Rua São Francisco Xavier, 524, $1^{\circ}$ andar

bloco D, sl.1001 • Tels.: +55 21 2334-4088 / 4087 • http://www.e-publicacoes.uerj.br/index.php/polemica/index

http://www.labore.uerj.br • laboreuerj@yahoo.com.br 
funcionamento mental, que são suficientemente específicas para constituir a condição necessária para o surgimento de tais condutas, embora não o bastante para que estas sejam uma resposta inevitável.

McDougall (2003) escolhe a palavra 'adição' para substituir o termo equivalente francês 'toxicomania'. Segundo a autora, o termo ‘adição' se refere a um estado de escravidão, portanto, a uma luta desigual do sujeito com parte de si mesmo.

Já a etimologia da palavra 'toxicomania' sugere que o sujeito tem intensão de causar mal a si mesmo, envenenar-se pela busca insistente de uma substância tóxica. No entanto, em sendo escravo do seu objeto, essa não poderia ser a meta do sujeito. Testemunhou-se nesses casos o objeto de adição sendo investido de qualidades benéficas; trata-se de um objeto de prazer utilizado para atenuar estados afetivos intoleráveis. Apenas em um segundo momento que esse mesmo objeto se torna persecutório.

Segundo McDougall, (2000), a vulnerabilidade egóica dos sujeitos adictos é consequência do relativo fracasso das internalizações precoces que asseguram as bases narcísicas suficientemente estáveis para garantir um sentimento de segurança e continuidade, capazes de se manter, principalmente, graças aos recursos do próprio sujeito.

\footnotetext{
Por trás de qualquer organização aditiva, encontramos a mãe arcaica, a mãe-droga, aquela que não pode ser internalizada de modo estável no mundo interno da criança. Esta falha fundamental corre o risco de produzir desastres psíquicos em cadeia. $\mathrm{O}$ sujeito incorre no perigo de ser obrigado a procurar sem descanso que um objeto do mundo externo desempenhe o papel do objeto interno faltante ou danificado, falta simbólica, mas também falta no imaginário, pois uma interdição implícita de fantasiar livremente está comprometida nessa problemática (MCDOUGALL, 2000, p. 103).
}

Para a autora, a economia aditiva encontra suas origens nas primeiras vivências de troca entre a mãe e o bebê. E a problemática estaria mais na angústia de perder o objeto primário do que na castração. Quando essa angústia não é transformada pela introjeção do objeto perdido em objeto interno (introjeção normal e apagamento do objeto absolutamente necessário), haverá, em seu lugar, uma busca insaciável e ilusória no mundo externo para encontrar o objeto ausente.

Seguindo a linha de pensamento proposta no presente artigo, o comportamento aditivo em relação à comida possui amalgamas nas raízes das falhas advindas da introjeção canibal e inapropriada do objeto absolutamente necessário (objeto primário) que dessa forma não se deixa negativar. A comida representa, nesses casos, o objeto externo capaz de oferecer um alívio ao sujeito, mesmo que seja um alívio temporário e inadequado.

\section{POLÊM!CA LABORE}

Polêmica - Revista Eletrônica da Uerj - Rua São Francisco Xavier, 524, $1^{\circ}$ andar bloco D, sl.1001 • Tels.: +55 21 2334-4088 / 4087 • http://www.e-publicacoes.uerj.br/index.php/polemica/index http://www.labore.uerj.br • laboreuerj@yahoo.com.br 
Com a introjeção canibal do objeto absolutamente necessário, o objeto não é negado e posto à distância, logo, não pode desdobrar-se em uma multiplicidade de objetos substitutivos e contingentes, o que gera a fixação em um único objeto. A impossibilidade de superação da dependência do sujeito em relação ao objeto inviabiliza a expansão de seus investimentos libidinais em direção a um vasto campo de objetos substitutos.

Contudo, McDougall, (2000) chama atenção para um fato: apesar da carência precoce na organização psíquica, é preciso observar que, muitas vezes, essa forte fragilidade de uma parte da personalidade não impede um bom funcionamento de outros setores da atividade do ego. Pode ser que essa falha precoce seja parcial, ligada apenas a certos impulsos pulsionais e não a outros.

\section{$\underline{\text { Impulsividade e Compulsão }}$}

Na clínica dos TAs, ao ouvir os pacientes com CA atentamente, é possível notar distinções entre o impulso que desencadeia a primeira mordida e o comer compulsivo que pode vir em sequência, sem freios ou barreiras internas capazes de cedê-lo.

Por outro lado, a escuta dos aspectos aditivos da CA, descritos no tópico anterior, nos fazem pensar na relação de fixação com o objeto comida. Essas particularidades convocam a reflexão sobre as diferenças entre esses constructos conceituais para uma melhor compreensão e abordagem deles no contexto dos TAs e da CA.

Por vezes, o impulso de comer algo não desencadeia uma CA. Frequentemente, impulsividade e compulsão ocorrem conjugadas numa sequência, mas não invariavelmente. Em algumas ocasiões, a CA tem seu início planejado: o sujeito sai para comprar determinados alimentos, encontra o momento e o lugar em que estará sozinho para iniciá-la. Porém seu desenvolvimento e seu fim não podem ser preditos. Ele começa comendo o que quer e termina comendo o que encontra pela frente, chegando em alguns casos a comer comida fria, combinações bizarras e até mesmo comida do lixo ou fora da validade (estragada). Nesses casos, a (não) interrupção do ato compulsivo é o que chama nossa atenção (VIANNA, 2019).

Em outras situações, o impulso diante da visão ou oportunidade de comer algo é o estopim para o comportamento compulsivo, podendo vir seguido de argumentos como os ilustrados nas vinhetas abaixo:

Já comi algo que engorda mesmo então não tenho mais motivo para me controlar.

\section{POLÊM!CA $\mid$ LABORE}

Polêmica - Revista Eletrônica da Uerj - Rua São Francisco Xavier, 524, $1^{\circ}$ andar bloco D, sl.1001 • Tels.: +55 21 2334-4088 / 4087 • http://www.e-publicacoes.uerj.br/index.php/polemica/index http://www.labore.uerj.br • laboreuerj@yahoo.com.br 
Não posso comer biscoito, quando pego só consigo parar quando acaba, não dá para guardar, ele fica me chamando.

A impulsividade, nessas configurações, possui um papel relevante na dinâmica da CA. Laplanche e Pontalis ao falarem sobre o tema, afirmam:

[...] Pela sua raiz, compulsão se inscreve, em francês [como em português], numa série, ao lado de pulsão e de impulso. Entre compulsão e pulsão, este parentesco etimológico corresponde bem à noção freudiana de Zwang. Entre compulsão e impulso, o uso estabelece diferenças sensíveis. Impulso designa o aparecimento súbito, sentido como urgente, de uma tendência para realizar este ou aquele ato, este se efetuando fora de qualquer controle e geralmente sobre o domínio da emoção; não se encontra nesse conceito nem a luta nem a complexidade da compulsão obsessiva, nem o caráter organizado segundo uma certa encenação fantasística da compulsão à repetição [...] No vocabulário freudiano, Zwang é utilizado para designar uma força interna imperativa. A palavra é empregada a maior parte das vezes no quadro da neurose obsessiva. Implica, então, que o sujeito se sente constrangido por essa força a agir, a pensar de determinada maneira, e luta contra ela (2001, p. 86-87).

Vaughan e Salzman, (1996) diferem comportamentos compulsivos de atos impulsivos, colocando esses últimos como resultado do desequilíbrio entre a força dos impulsos e afetos e a capacidade de modulação do ego, com a função de aliviar a angústia através da descarga pulsional. Assim, nos sujeitos impulsivos, o ego frágil, com pouca capacidade de continência, não prospera em conter a demanda pulsional.

Ainda segundo os autores, os comportamentos compulsivos são resultantes da tentativa do ego em conter a expressão pulsional. A angústia gerada pelo movimento pulsional sinaliza para o ego a mobilização de defesas específicas, ao passo que, em outros sujeitos, as instâncias psíquicas formariam um acordo no qual ambos os polos do conflito obteriam satisfação parcial.

Seguindo a linha de raciocínio teórico para a leitura da CA aqui traçada, com a introjeção canibal do objeto absolutamente necessário ocorre uma falha na internalização da função pulsionalizante desse objeto, responsável pelo despertar dos movimentos pulsionais, assim como por conter as pulsões.

Uma leitura teórica possível da impulsividade e compulsividade na CA seria a vinculação desses processos com a falha na internalização das funções de despertar e conter as pulsões. Em outras palavras, a internalização inapropriada da função de despertar as pulsões poderia levar à dificuldade de controlar a impulsividade, enquanto a falha na internalização da função de conter as pulsões estaria relacionada com a inabilidade para interromper a voracidade compulsiva uma vez desencadeada.

\section{POLÊM!CA $\mid$ LABORE}

Polêmica - Revista Eletrônica da Uerj - Rua São Francisco Xavier, 524, $1^{\circ}$ andar bloco D, sl.1001 • Tels.: +55 21 2334-4088 / 4087 • http://www.e-publicacoes.uerj.br/index.php/polemica/index http://www.labore.uerj.br • laboreuerj@yahoo.com.br 
Quando se extravia o trabalho do negativo, na ausência de um vazio interno estruturante, o objeto não é internalizado adequadamente e as funções estimulantes e de contenção da pulsão ficam comprometidas. Nos sujeitos impulsivos, o ego fragilizado é inapto para lidar com o movimento inicial pulsional, despertando-o de forma impetuosa e intempestiva, gerando ações impensadas e inconsequentes. Enquanto o que caracteriza a compulsividade é a inabilidade egóica de conter a pulsão uma vez desencadeada e assim, por fim, ao comportamento repetitivo e abusivo.

\section{Conclusão}

Vimos, ao longo deste artigo, que a introjeção canibal do objeto absolutamente necessário faz com que ocorra uma identificação com o objeto destroçado e destituído de valor. Dessa forma, não se edifica o vazio interno estruturante, fundamental para o bom funcionamento simbólico e o estabelecimento de bases narcísicas seguras.

Nesses casos, em que se extravia o trabalho do negativo, em vez de prestar-se aos processos de constituição psíquica, o objeto não pode despertar as pulsões e/ou contê-las, comprometendo diretamente sua capacidade de lidar com a dinâmica pulsional.

Essa dificuldade diante das forças pulsionais pode nos ajudar a pensar a impulsividade que leva a ações não premeditadas e inconsequentes, assim como a ausência de freios da CA, que só consegue ser interrompida por elementos externos ao sujeito ou pelo mal-estar físico decorrente do empanturramento (NOVAES, 2012, 2018).

Comparando a CA com o modelo das adições, chamamos atenção para a fixação no objeto comida, que ocorre quando o objeto primário não se deixa apagar, não é posto a distância e não se reedita em uma multiplicidade de outros objetos contingentes e substituíveis.

A fixação em um único objeto, típica das adições, aponta para a vulnerabilidade egóica presente nesses casos. Como afirma McDougall (2000), estas seriam consequências do relativo fracasso das internalizações precoces, que deveriam estabelecer as bases narcísicas suficientemente estáveis para assegurar um sentimento de segurança e continuidade, mantidos prioritariamente pelos recursos do próprio sujeito.

O tratamento da compulsão alimentar, tanto em sujeitos obesos quanto nos eutróficos, deve abordar fundamentalmente os aspectos psíquicos que levaram a fixação no objeto comida, a fragilidade narcísica e o comprometimento da dinâmica pulsional. Os aspectos comportamentais, nutricionais e socioculturais também são relevantes para compreensão e

\section{POLÊM!CA $\mid$ LABORÉ}

Polêmica - Revista Eletrônica da Uerj - Rua São Francisco Xavier, 524, $1^{\circ}$ andar

bloco D, sl.1001 • Tels.: +55 21 2334-4088 / 4087 • http://www.e-publicacoes.uerj.br/index.php/polemica/index

http://www.labore.uerj.br • laboreuerj@yahoo.com.br 
abordagem terapêutica, trazendo elementos importantes para o manejo de cada caso. Entretanto, eles não se sobrepujam a dimensão constitutiva da subjetividade que avaliza esta disfunção alimentar.

\section{Referências}

APA - AMERICAN PSYCHIATRIC ASSOCIATION. Diagnostic and Statistical Manual of Mental Disorders. (DSM-5). Washington, DC: American Psychiatric Association, 2013.

APPOLINÁRIO, J. C.; COUTINHO, W. O transtorno do comer compulsivo: revisão de literatura. Jornal Brasileiro de Psiquiatria, v. 44, n. 1, p. 45-61, out. 1995.

AZEVEDO, A. P.; SANTOS, C. C.; FONSECA, D. C. Transtorno da compulsão alimentar periódica. Revista de Psiquiatria Clínica, São Paulo, v. 31, n. 4, p. 170-172, 2004.

BAUDRILLARD. J. A sociedade de consumo. Rio de Janeiro: Zahar, 1970. (Coleção Ciências Sociais passo a passo).

BOURDIEU, P. Le sens patique. Paris: Ed. Minuit, 1980. (Collection Le sens commun).

BRUCH, H. Eating Disorders, Obesity, Anorexia Nervosa and the Person Within. London: Routledge and Kegan Paul, 1974.

COUTINHO, W. Obesidade: conceitos e classificação. In: NUNES, M. A. et al. Transtornos alimentares e obesidade. Porto alegre: Artmed, 1998. p. 197-202.

DUCHESNE, M.; APPOLINÁRIO, J. C.; RANGÉ, B. P.; FREITAS, S.; PAPELBAUM, M.; COUTINHO, W. Evidências sobre a terapia cognitivo-comportamental no tratamento de obesos com transtorno da compulsão alimentar periódica. Revista de Psiquiatria, Porto Alegre, v. 29, n. 1, p. 80-92, abr. 2007.

FIGUEIREDO, L. C. Psicanálise: elementos para clínica contemporânea. São Paulo: Escuta, 2003.

CINTRA, E. Lendo André Green: O trabalho do negativo e o paciente limite. In: CARDOSO, M. (Org.). Limites. São Paulo: Escuta, 2004.

FIORINI, H. J. Teoria e técnica de psicoterapias. Rio de Janeiro: Martins Fontes, 2004.

Comentários ao artigo de Helen Deutsch. In: URRIBARRI, R. (Org.). Anorexia e Bulimia. São Paulo: Escuta, 1999.

FORTES, I. A dimensão do excesso no sofrimento contemporâneo. Pulsional Revista de Psicanálise, São Paulo, v. 21, n. 3, p. 63-74, set. 2008.

FREITAS, S.; GORENSTEIN, C.; APPOLINÁRIO, J. C. Instrumentos para a avaliação dos transtornos alimentares. Revista Brasileira de Psiquiatria, São Paulo, v. 24, n. 3, p. 34-38, 2002.

FREITAS, S.; LOPES, C. S.; COUTINHO, W.; APPOLINARIO, J. C. Tradução e adaptação para o português da Escala de Compulsão Alimentar Periódica. Revista Brasileira de Psiquiatria, v. 23, n. 4, p. 215-220, 2001.

FREUD, S. Novas Conferências Introdutórias sobre a Psicanálise. In: Edição Standard Brasileira das Obras completas de Sigmund Freud. Rio de Janeiro: Imago, 1996a. V. XXII. (Trabalho original publicado em1933).

\section{POLÊM!CA $\mid$ LABORÊ}

Polêmica - Revista Eletrônica da Uerj - Rua São Francisco Xavier, 524, $1^{\circ}$ andar

bloco D, sl.1001 • Tels.: +55 21 2334-4088 / 4087 • http://www.e-publicacoes.uerj.br/index.php/polemica/index

http://www.labore.uerj.br • laboreuerj@yahoo.com.br 
FREUD, S. Inibição, sintoma e ansiedade. In: Edição Standard Brasileira das Obras Psicológicas

Completas. (v. XX). Rio de Janeiro: Imago, 1996b. (Trabalho original publicado em 1926).

Luto e Melancolia. In: Edição Standard Brasileira das Obras completas de Sigmund Freud. (v. XIV, p. 281).Rio de Janeiro: Imago, 1996c. (Trabalho original publicado em 1915).

Estudos sobre a histeria. In: Edição Standard Brasileira das Obras Psicológicas Completas. v. II. Rio de Janeiro: Imago, 1996d. (Trabalho original publicado em 1895).

GARCIA, C. Os estados limite e o trabalho do negativo: uma contribuição de André Green para a clínica contemporânea. Revista Mal-estar e Subjetividade, Fortaleza, v. 7, n. 1, p. 123-135, mar. 2007.

GREEN, A. O trabalho do negativo. Porto Alegre: Artmed, 2009.

Orientação para uma psicanálise contemporânea. Rio de Janeiro: Imago, 2008.

_. Narcisismo de vida, narcisismo de morte. São Paulo: Escuta, 1988a.

1988b.

Pulsão de morte, negativo, função desobjetalizante. In: Pulsão de morte. São Paulo: Escuta,

O analista, a simbolização e a ausência no contexto analítico. In: Green, A. Sobre a loucura pessoal. (C. A Pavanelli. Trad.). Rio de Janeiro: Imago, 1988c. p. 36-65. $1986 / 1990$

Conferências Brasileiras de André Green: Metapsicologia dos Limites. Rio de Janeiro: Imago,

La Double Limite. Nouvelle Revue de Psychanalyse, v. 25, p. 267-283, 1982.

O conceito de fronteiriço. In: Sobre a Loucura Pessoal. Rio de Janeiro: Imago, 1977a/1988.

A alucinação negativa. In: O trabalho do negativo. Porto Alegre: Artmed, 1977b/2010.

GURFINKEL, D. Adicções: da perversão da pulsão à patologia dos objetos transicionais. Revista Psychê, São Paulo, v. 11, n. 20, p. 13-28, jan./jun. 2007.

A pulsão e seu objeto-droga: estudo psicanalítico sobre a toxicomania. Petrópolis: Vozes, 1996.

HALMI, K. A. Eating Disorders: Anorexia Nervosa, Bulimia Nervosa and Obesity. In: HALES, R.E.;

YUDOFSKY, S. C.; TALBOTT, J. A. (Org.). Textbook of Psychiatry. 2. ed. Washington, DC: American Psychiatric Press, 1994. p. 857-875.

ISSACS, S. Natureza e a função da fantasia. In: KLEIN, M; HEIMANN, P.; ISSACS, S.; RIVIÈRE, J. Os progressos da psicanálise. Rio de Janeiro: Guanabara, 1986.

JEAMMET, P. Desregulações narcísicas. In: BRUSSET, B.; COUVREUR, C.; FINE, A. A Bulimia. São Paulo: Escuta, 2003.

Abordagem psicanalítica dos transtornos da conduta alimentar. In: URRIBARRI, R. Anorexia e Bulimia. São Paulo: Escuta, 1999a.

As condutas bulímicas como modalidade de acomodação das desregulações narcísicas e objetais. In: URRIBARRI, R. (Org). Anorexia e Bulimia. São Paulo: Escuta, 1999b. p.178-192.

KEHL, M. R. As máquinas falantes. In: NOVAES, A. (Org.). O homem máquina: a ciência manipula o corpo. São Paulo: Companhia das Letras, 2003.

\section{POLÊM!CA $\mid$ LABORE}

Polêmica - Revista Eletrônica da Uerj - Rua São Francisco Xavier, 524, $1^{\circ}$ andar bloco D, sl.1001 • Tels.: +55 21 2334-4088 / 4087 • http://www.e-publicacoes.uerj.br/index.php/polemica/index http://www.labore.uerj.br • laboreuerj@yahoo.com.br 
KESTEMBERG, E.; DECOBERT, S. La faim et le corps. Paris: PUF, 1972.

KLEIN, M. (1932). A psicanálise de crianças. Rio de Janeiro: Imago, 1997.

(1933). O desenvolvimento inicial da consciência na criança. In: KLEIN, M. Amor, culpa e reparação e outros trabalhos. Rio de Janeiro: Imago, 1996.

(1935). O luto e suas relações com os estados maníaco-depressivos (1940). In: Klein, M. Amor, culpa e reparação e outros trabalhos. Rio de Janeiro: Imago, 1996.

(1935). Uma contribuição para a psicogênese dos estados maníaco-depressivos. In: Klein, M. Amor, culpa e reparação e outros trabalhos. Rio de Janeiro: Imago, 1996.

1991.

(1952). Algumas conclusões teóricas relativas à vida emocional do bebê. Rio de Janeiro: Zahar,

Os progressos da psicanálise .4. ed.. Rio de Janeiro: Zahar, 1986.

(1946). Inveja e gratidão e outros trabalhos. Rio de Janeiro: Imago, 1963.

Inveja e gratidão e outros trabalhos. Rio de Janeiro: Imago, 1957. (Obras completas de Melanie Klein, v. III).

LAPLANCHE, J.; PONTALIS, J.B. Vocabulário de Psicanálise. São Paulo: Martins Fontes, 2001.

LASK, B. Aetiology. In: LASK, B.; BRYANT-WAUGHT, R. (Ed.) Anorexia Nervosa and Related Eating Disorders in Childhood and Adolescence. East Sussex: Psychology Pressp, 2000. p. 63-79.

MCDOUGALL, J. Sobre a bulimia. In: BRUSSET, B.; COUVREUR, C.; Fine, A. A Bulimia. São Paulo: Escuta, 2003.

Corpo e História. São Paulo: Casa do Psicólogo, 2000.

Teatro dos corpos: o psicossoma em psicanálise. São Paulo: Martins Fontes, 2000.

MIRANDA, M. R. Anorexia nervosa e bulimia à luz da Psicanálise - a complexidade da relação mãe-filha. 2003. 208 f. Tese (Doutorado em Psicologia) - Pontifícia Universidade Católica de São Paulo, São Paulo, 2003.

MITCHEL J. The Oupatient Treatment of Eating Disorders. Minneapolis: University of Minessota Press, 2001.

NOVAES, J. V. Abundância no deserto: Notas sobre obesidade feminina e devastação. In: NOVAES, J. V.; VILHENA, J. (Org.). O que pode um corpo? Diálogos Interdisciplinares. Curitiba: Appris, 2019. p. 65-82.

Saco vazia não fica em pé: sobre a obesidade nas classes populares brasileiras. In: NOVAES, J. V.; VILHENA, J. (Org.). O corpo que nos possui: corporeidade e suas conexões. Curitiba: Appris, 2018. p. 167184.

Empanturrados de afeto, envergonhados da fome: corpo, maternidade e obesidade infantil. In: VILHENA, J.; NOVAES, J. V. (Org.). Que corpo é este que anda sempre comigo? Corpo, imagem e sofrimento psíquico. Curitiba: Appris, 2012. p. 111-126.

Com que corpo eu vou? Sociabilidades e usos do corpo nas mulheres das camadas altas e populares. Rio de Janeiro: Ed.PUC/Pallas, 2010.

Sobre a tirania da beleza. Revista Polêmica, Rio de Janeiro, v. 18, p. 18, 2007.

\section{POLÊM!CA $\mid$ LABORÊ}

Polêmica - Revista Eletrônica da Uerj - Rua São Francisco Xavier, 524, $1^{\circ}$ andar

bloco D, sl.1001 • Tels.: +55 21 2334-4088 / 4087 • http://www.e-publicacoes.uerj.br/index.php/polemica/index

http://www.labore.uerj.br • laboreuerj@yahoo.com.br 
NOVAES, J. V. O intolerável peso da feiura: sobre as mulheres e seus corpos. Rio de Janeiro: Ed. PUC/Garamnond, 2006.

NUNES, M. A. Epidemiologia dos transtornos alimentares. In: NUNES, M. A.; APPOLINÁRIO, J. C.; GAlVÃO, A. L.; COUTINHO, W. (Org.). Transtornos Alimentares e Obesidade. 2. ed. Porto Alegre: Artmed, 2006. p. 51-57.

OLIVEIRA, T. U. V.; AMARAL, T. V. F. O Complexo de Édipo: Uma comparação entre Melanie Klein e Sigmund Freud. Mosaico: Estudos em Psicologia, Belo Horizonte, v. 3, n. 1, p. 1-8, 2009.

PINHEIRO, N.N. B. Narrativas corporais e sobrevivência psíquica: algumas considerações sobre os processos primitivos da constituição subjetiva. In: NOVAES, J. V.; VILHENA, J. (Org). O que pode um corpo? Diálogos Interdisciplinares. Curitiba: Ed. Appris, 2018. p.321-334.

SCAZUFCA, A. C.; BERLINK, M. T. Sobre o tratamento psicoterapêutico da anorexia e da bulimia. In: CARDOSO, M. R. (Org.). Limites. São Paulo: Escuta, 2004. p. 89-106.

SOCIEDADE BRASILEIRA DE CIRURGIA BARIÁTRICA E METABÓLICA - SBCBM. Home. Disponível em: https://www.sbcbm.org.br/. Acesso em: 30 out. 2019.

VAUGHAN, S. C.; SALZMAN, L. Antianxiaty funtion of impulsivity and compulsivity. In: OLDHAM, J. M.; HOLLANDER, E.; SKODOL, A. E. (Org.). Impulsivity and compulsivity. Washington, DC, US: American Psychiatric Association, 1996. p. 167-194.

VIANNA, M. Do bisturi ao divã: cirurgia bariátrica, compulsão alimentar e psicanálise. Curitiba: Appris, 2019.

Da geladeira ao divã: psicanálise da compulsão alimentar. Curitiba: Appris, 2016.

VILHENA, J.; NOVAES, J. V.; ROSA, C. M. A sombra de um corpo que se anuncia: corpo, imagem e envelhecimento. Revista Latinoamericana de Psicopatologia Fundamental (Impresso), São Paulo, v. 17, n. 2, p. 251-264, jun. 2014.

NOVAES. J. Corpo para que te quero? Usos, abusos e desusos. Curitiba: Ed. Appris/PUC, 2012.

NOVAES, J. V.; ROCHA, L. Comendo, comendo e não se satisfazendo apenas uma questão cirúrgica? Obesidade mórbida e o culto ao corpo na sociedade contemporânea. Revista Mal-Estar e Subjetividade, Fortaleza, v. 8, n. 2, p. 379-406, jun. 2008.

MEDEIROS, S.; NOVAES, J. V. A violência da imagem: a estética, o feminino e a contemporaneidade. Revista Mal-Estar e Subjetividade, Fortaleza, v. 5, n. 1, p. 111-146, mar. 2005.

WINNICOTT, D. W. (1958). A posição depressiva no desenvolvimento emocional normal. In: . Da pediatria à psicanálise - Obras escolhidas. Rio de Janeiro: Imago, 2000a.

(1958). A tendência anti-social. In Da pediatria à psicanálise - Obras escolhidas. Rio de Janeiro: Imago, 2000b.

(1958). O papel do espelho da mãe e da família no desenvolvimento infantil. In:

Psicanálise - Obras escolhidas. Rio de Janeiro: Imago, 2000c.

Os bebês e suas mães. São Paulo: Martins Fontes, 1999.

O brincar e realidade. Rio de Janeiro: Imago, 1975.

(1974). La crainte de l'effondrement. Nouvelle Revue de Psychanalyse, Paris: Gallimarde, v. 11, p. 42.

WORLD HEALTH ORGANIZATION. Home. Disponível em: https://www.who.int/. Acesso em: 01 maio 2019.

\section{POLÊM!CA LABORE}

Polêmica - Revista Eletrônica da Uerj - Rua São Francisco Xavier, 524, $1^{\circ}$ andar

bloco D, sl.1001 • Tels.: +55 21 2334-4088 / 4087 • http://www.e-publicacoes.uerj.br/index.php/polemica/index http://www.labore.uerj.br • laboreuerj@yahoo.com.br 
ZWAAN, M.; HILBERT, A.; SWAN-KREMEIER, L.; SIMONICH, H.; LANCASTER, K.; HOWELL, L. M. et al. Comprehensive interview assessment of eating behavior 18-35 months after gastric bypass surgery for morbid obesity. Surg. Obes. Relat. Dis., v. 6, n. 1, p. 79-85, jan. 2010.

Recebido em: 30/03/2019.

Aceito em: 30/05/2019.

\section{POLÊM!CA LABORE}

Polêmica - Revista Eletrônica da Uerj - Rua São Francisco Xavier, 524, $1^{\circ}$ andar bloco D, sl.1001 • Tels.: +55 21 2334-4088 / 4087 • http://www.e-publicacoes.uerj.br/index.php/polemica/index http://www.labore.uerj.br • laboreuerj@yahoo.com.br 